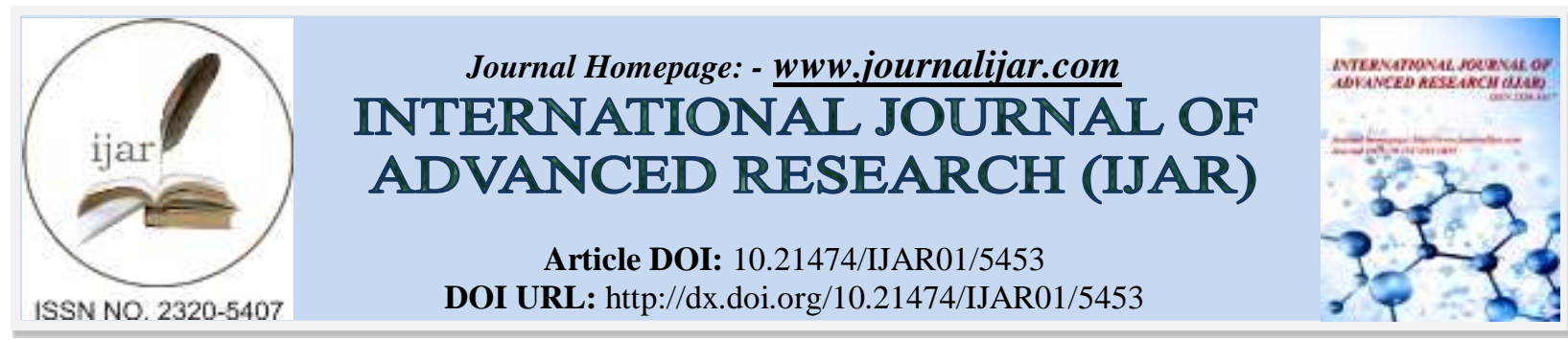

RESEARCH ARTICLE

\title{
ENDOMETRIAL PATTERNS IN ABNORMAL UTERINE BLEEDING -A STUDY OF 300 CASES IN A TERTIARY CARE HOSPITAL IN SOUTH INDIA.
}

\section{Dr. Tejashwini Reddy Punuru ${ }^{1}$, Dr. Vimal Chander $\mathbf{R}^{2}$ and Prof. Dr. Chitra Srinivasan ${ }^{3}$.}

1. Resident of Pathology, Department of Pathology, Saveetha Medical College and Hospital, Chennai, TamilNadu, India.

2. Associate Professor, Department of Pathology, Saveetha Medical College and Hospital, Chennai, TamilNadu, India.

3. Professor and Head of the Department, Department of Pathology, Saveetha Medical College and Hospital, Chennai, Tamil Nadu, India.

\section{Manuscript Info}

(........................

Manuscript History

Received: 17 July 2017

Final Accepted: 19 August 2017

Published: September 2017

Key words:-

Abnormal uterine bleeding

(AUB),Endometrium, Histopathology.

\section{Abstract}

Background: Abnormal uterine bleeding (AUB) is defined as changes in frequency of menstruation, duration of flow or amount of blood loss. Abnormal uterine bleeding (AUB) is the commonest presenting symptom in Gynaecology outpatient department. Endometrial sampling could be effectively used as a first diagnostic step in abnormal uterine bleeding. The aim of the study was to analyze the histomorphological patterns of endometrium in patients presenting with abnormal uterine bleeding and also to determine the incidence of abnormal uterine bleeding in various age groups.

Materials and Methods: All cases of abnormal uterine bleeding with a probable endometrial cause received in the Department of Pathology, Saveetha Medical College, Chennai for a period of 12 months from January 2016 to January 2017 were included in this retrospective study. Data was analyzed using Statistical Package for the Social Sciences (SPSS) version.

Results: The most common age group presenting with abnormal uterine bleeding was 18-40 years. The commonest non organic lesion was proliferative endometrium (39\%),followed by secretory pattern (24\%), while in organic lesions the most common cause of abnormal uterine bleeding was pregnancy related.

Conclusion: The cases were clustered around perimenopause. Histopathological evaluation of endometrial samples is highly helpful especially in women over the age of 40 years to rule out premalignant and malignancy lesions of endometrium.

Copy Right, IJAR, 2017,. All rights reserved.

\section{Introduction:-}

Abnormal uterine bleeding is defined as any bleeding from uterus other than menstrual bleeding. Since long it has been classified as abnormal uterine bleeding secondary to organic pathology or dysfunctional uterine bleeding. ${ }^{(1)}$ The most common presentation are menorrhagia, polymenorrhoea, metrorrhagia and instrumental bleeding. ${ }^{(2)}$. AUB may present in many patterns and can be evaluated by histopathology which remains the diagnostic standard for the 
clinical diagnosis of endometrial pathology.AUB may be the symptom of endometrial carcinoma in $8-50 \%$ of cases. $(3,4)$

As AUB is the most common symptom presented in the Gynaecology outpatient department it is necessary to evaluate the nature of disease and to rule out malignancy, so that it aids in better prognosis of the patient. ${ }^{(1)}$ Until the pathology of underlying causes is accurately diagnosed, correct method of treatment are impossible ${ }^{(5)}$. Endometrial biopsy or curettage could be a safe and effective diagnostic step in evaluation of abnormal uterine bleeding after ruling out medical causes. ${ }^{(6)}$

\section{Objectives:-}

1.To determine the incidence of abnormal uterine bleeding in various age groups.

2.To evaluate the histopathological patterns of endometrium in patients presenting with AUB.

\section{Materials and Methods:-}

This retrospective study included 300 cases with clinical diagnosis of AUB during a period of one year from January 2016 - January 2017 at Saveetha Medical College, Chennai. The endometrial samplings of patients diagnosed with Abnormal uterine bleeding were formalin fixed and routinely processed. Patient with isolated endometrial causes of AUB were included in the study. The tissues which were ill fixed and inadequate samples were excluded from the study. The paraffin blocks were sectioned at 4-5 $\mu$. The sections were then stained by haemotoxylin and eosin (H\&E). Microscopic examination was done by two pathologists, individually to reduce observer bias. The patients were divided into three age groups viz, Group I (reproductive age group):18-40 years, Group II(perimenopausal age group): 41-45 years, and Group III (postmenopausal): 445 years. The histopathological changes of endometrium were classified as AUB due to non-organic causes and AUB due to organic causes.

The non-organic causes of AUB included :

1.Secretory phase endometrium

2.Proliferative phase endometrium

3.Atrophic endometrium

4.Disordered proliferative phase endometrium

The organic causes of AUB included :

1.Endometrial hyperplasia

2.Endometrial Polyp

3.Complications of pregnancy

4.Endometrial carcinoma

The data was collected and analyzed. Analysis was done using Statistical Package for the Social Sciences(SPSS ) software and the data is represented as tables and figures where necessary.

\section{Results:-}

In the study a total of 300 samples presenting with abnormal uterine bleeding were obtained of which 7 samples were unsatisfactory. Two hundred and twenty three cases $(74.3 \%)$ cases revealed no organic pathology while seventy cases $(23.3 \%)$ showed a definite pathology of the endometrium. The unsatisfactory samples were 7 $(2.3 \%)$ (Table 1). The age of the patients ranged from $18-70$ years and the maximum no. of cases observed were in the reproductive age group (18-40).

Non-organic lesions of endometrium : Out of the 223 non-organic causes of AUB , normal physiological changes like proliferative,secretory and atrophic endometrium were most common and seen in 117 cases(39\%),72 cases(24\%), and 14 cases $(4.7 \%)$ respectively. Disordered proliferative endometrium was seen in 20 $\operatorname{cases}(6.6 \%)$.(Table 2).

Organic Causes: Among the 70 organic causes of endometrium, different lesions found were due to complications of pregnancy in 44 cases(14.7\%), endometrial polyp in 6 cases(2\%), endometrial hyperplasia in 15 cases(5\%), endometrial carcinoma in 5 cases(1.7\%). The most common organic lesion in the age group 18-40 years was pregnancy related, in 40-45 year age group was due to endometrial hyperplasia and in the age group above 45 years it was due to carcinoma.(Table 3 ). 
Table 1 Main outcome of endometrial samples presenting with AUB

\begin{tabular}{|l|l|}
\hline Type of Lesion & No. (\%) of cases \\
\hline Non-organic or functional lesions & $223(74.3 \%)$ \\
\hline Organic lesions & $70(23.3 \%)$ \\
\hline Unsatisfactory & $7(2.3 \%)$ \\
\hline Total & $300(100 \%)$ \\
\hline
\end{tabular}

Table 2 Non-organic causes of AUB in different age groups

\begin{tabular}{|l|l|l|l|l|}
\hline Causes & $\mathbf{1 8 - 4 0}$ years & $\mathbf{4 1 - 4 5}$ years & $\mathbf{> 4 5}$ years & Total \\
\hline Proliferative phase & 53 & 56 & 8 & 117 \\
\hline Secretory phase & 45 & 26 & 1 & 72 \\
\hline Disordered proliferative phase & 7 & 9 & 4 & 20 \\
\hline Atrophic endometrium & - & 6 & 8 & 14 \\
\hline Total & 105 & 97 & 21 & 223 \\
\hline
\end{tabular}

Table 3:- Organic causes of AUB in different age groups

\begin{tabular}{|l|l|l|l|l|}
\hline Causes & $\mathbf{1 8 - 4 0}$ years & $\mathbf{4 1 - 4 5}$ years & $\mathbf{> 4 5}$ years & Total \\
\hline Complications of pregnancy & 43 & 1 & - & 44 \\
\hline Endometrial hyperplasia & 2 & 12 & 1 & 15 \\
\hline Endometrial polyp & 1 & 5 & - & 6 \\
\hline Endometrial carcinoma & - & - & 5 & 5 \\
\hline Total & 46 & 18 & 6 & 70 \\
\hline
\end{tabular}

\section{Discussion:-}

Abnormal uterine bleeding without structural pathology occurs in reproductive women of all ages but is more common in adolescent and perimenopausal women. ${ }^{(7)}$ The present study comprised of 300 cases of endometrial biopsies of woman of 18-70 years age received in our department. In the present study, the maximum incidence of AUB was in the age group 18-40 yrs age range. The incidence of AUB in $>45$ yrs of age was lower as compared to those between 18-45 yrs. In our study most of the cases (223) $74.3 \%$ were of non organic causes and (70) $23.3 \%$ cases were of organic origin.

Among the non organic causes of endometrial pattern in perimenopausal women, most common pattern was the proliferative endometrium (36.08). The cause of bleeding in the proliferative phase could be due to anovulatory cycle. These findings are similar to Vijay Kumar Bodal et al ${ }^{(8)}$ and Sadia Hameed et al. ${ }^{(1)}$ (Table 4)

Atrophic Endometrium is the second most common findings in postmenopausal women. The cause of bleeding in atrophic endometrium could be because of vascular variations anatomically or due to abnormal haemostatic mechanisms.

Secretory phase endometrium was found in $24 \%$ cases, which is similar as that reported by others $(38.4 \%, 35.4 \%)$ ${ }^{(1,9)}$. (Table 4)

We got $6.6 \%$ cases with disordered proliferative endometrium. This pattern is at one end of the spectrum of proliferative lesions of the endometrium which includes carcinoma at the other end with intervening stages of hyperplasia. The term "Disordered proliferative endometrium has been used in a number of ways and is somewhat difficult to define ${ }^{(4)}$ It denotes an endometrial appearance that is hyperplasic but without an increase in endometrial volume ${ }^{(4)}$.Disordered proliferative patterns resembles a simple hyperplasia, but the process is focal rather than diffuse.

Among the organic causes the most common cause of bleeding was due to pregnancy related (14.7\%).The second most common cause was endometrial hyperplasia $(5 \%)$ encountered. Endometrial hyperplasia was observed in 5\% of cases. K.Sajtha et al ${ }^{(2)}$ found it to be $25 \%$ which is higher than that of our findings(Table 4).Identifying lesions of endometrial hyperplasia is important as they are thought to be precursors of endometrial carcinoma. 
The incidence of endometrial polyps in our study is $2 \%$. An incidence of $(5.12 \%, 13.8 \%, 11.2 \%)$ were reported in other studies ${ }^{(2,5,6)}$ which is contrast to our study. (Table 4)

Endometrial carcinoma was reported in $1.7 \%$ of cases which is similar to the other author $2 \%$ and $3.3 \%$ respectively. ${ }^{(1,3)}$. This incidence was slightly higher than the results of Muzzaffar et $\mathrm{al}(0.4 \%)^{(9)}$ (Table 4).In our study one of the organic cause of AUB i.e. endometrial carcinoma was seen to be increasing with increase in age.

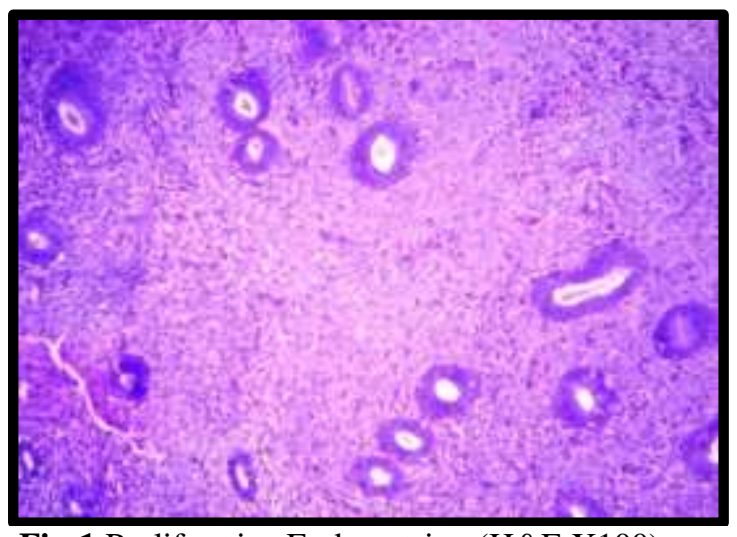

Fig:1 Proliferative Endometrium(H\&E X100)

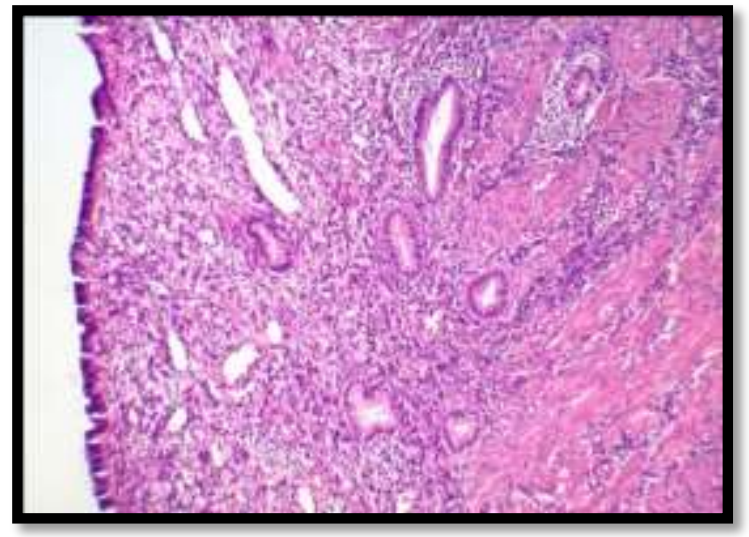

Fig:3 Atrophic Endometrium(H\&E X100)

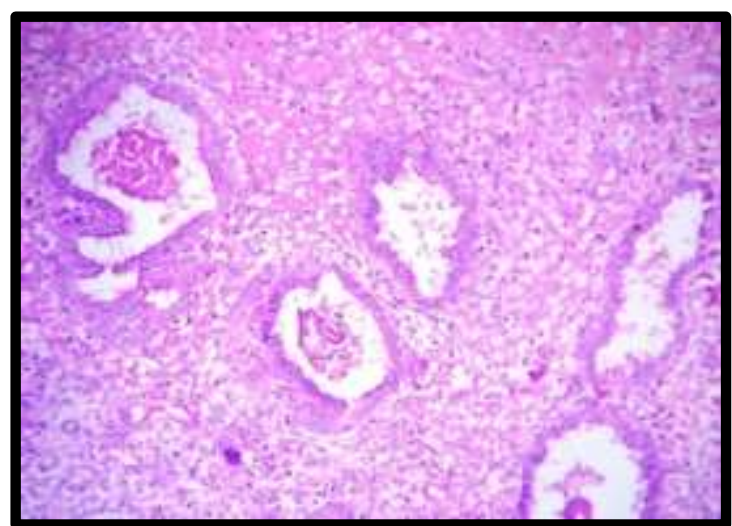

Fig:2 Secretory Endometrium(H\&E X100).

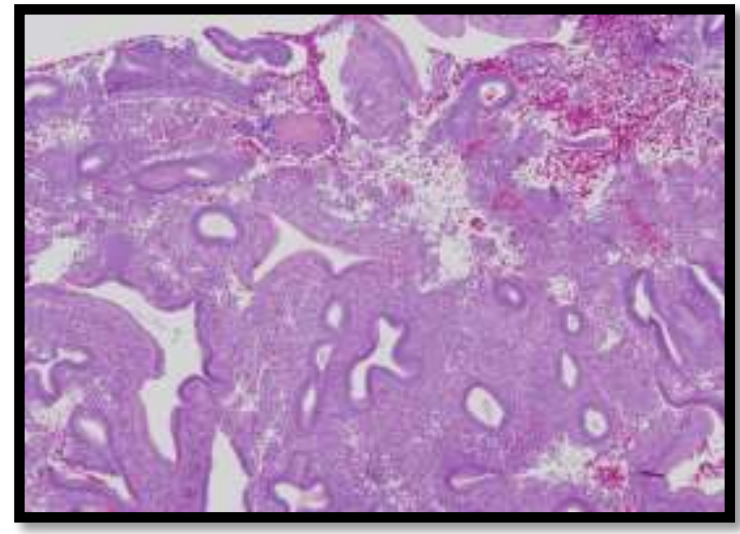

Fig:4 Disordered Proliferative Endometrium(H\&E $\mathrm{X} 100)$

Table 4:- Comparison Of Different Studies

\begin{tabular}{|c|c|c|c|c|c|c|c|c|c|}
\hline 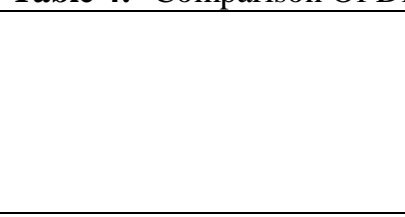 & $\begin{array}{l}\text { Vijay } \\
\text { Kum } \\
\text { ar et } \\
\text { al }\end{array}$ & $\begin{array}{l}\text { Kha } \\
\text { ns et } \\
\text { al }\end{array}$ & $\begin{array}{l}\text { Shazi } \\
\text { a } \\
\text { Fakh } \\
\text { ar et } \\
\text { al }\end{array}$ & $\begin{array}{l}\text { K.Sajit } \\
\text { ha et } \\
\text { al }\end{array}$ & $\begin{array}{l}\text { Bhoom } \\
\text { ika et } \\
\text { al }\end{array}$ & $\begin{array}{l}\text { Nad } \\
\text { ia et } \\
\text { al }\end{array}$ & $\begin{array}{l}\text { Doraisw } \\
\text { ami et al }\end{array}$ & $\begin{array}{l}\text { Muzzaf } \\
\text { far et al }\end{array}$ & $\begin{array}{l}\text { Prese } \\
\text { nt } \\
\text { Stud } \\
\text { y }\end{array}$ \\
\hline \multicolumn{10}{|l|}{ Non-organic causes } \\
\hline Proliferative phase & $\begin{array}{l}26.33 \\
\%\end{array}$ & $\begin{array}{l}46.6 \\
\%\end{array}$ & $54 \%$ & $12.2 \%$ & $21 \%$ & $\begin{array}{l}45.1 \\
\%\end{array}$ & - & $25.8 \%$ & $39 \%$ \\
\hline Secretory phase & $\begin{array}{l}25.33 \\
\%\end{array}$ & $\begin{array}{l}38.4 \\
\%\end{array}$ & $14 \%$ & $16.6 \%$ & $28.6 \%$ & $\begin{array}{l}21.6 \\
\%\end{array}$ & - & $35.4 \%$ & $24 \%$ \\
\hline $\begin{array}{l}\text { Disordered proliferative } \\
\text { phase }\end{array}$ & $\begin{array}{l}4.33 \\
\%\end{array}$ & - & - & $12.2 \%$ & $6.6 \%$ & $\begin{array}{l}1.96 \\
\%\end{array}$ & $20.5 \%$ & $0.8 \%$ & $6.6 \%$ \\
\hline Atrophic endometrium & $\begin{array}{l}2.33 \\
\%\end{array}$ & $1 \%$ & - & $5.13 \%$ & - & $\begin{array}{l}1.96 \\
\%\end{array}$ & $2.44 \%$ & $0.8 \%$ & $4.7 \%$ \\
\hline \multicolumn{10}{|l|}{ Organic causes } \\
\hline $\begin{array}{l}\text { Complications of } \\
\text { pregnancy }\end{array}$ & - & - & - & - & - & $\begin{array}{l}31.9 \\
\%\end{array}$ & $22.7 \%$ & - & $\begin{array}{l}14.7 \\
\%\end{array}$ \\
\hline
\end{tabular}




\begin{tabular}{|l|l|l|l|l|l|l|l|l|l|}
\hline Endometrial hyperplasia & $\begin{array}{l}12.67 \\
\%\end{array}$ & $9.2 \%$ & $19 \%$ & $25 \%$ & $26.6 \%$ & $\begin{array}{l}41.5 \\
\%\end{array}$ & $6.1 \%$ & $24.7 \%$ & $5 \%$ \\
\hline Endometrial polyp & $\begin{array}{l}2.67 \\
\%\end{array}$ & $0.6 \%$ & $4 \%$ & $5.12 \%$ & - & $\begin{array}{l}13.8 \\
\%\end{array}$ & $11.2 \%$ & $1.2 \%$ & $2 \%$ \\
\hline Endometrial Malignancy & $6 \%$ & $0.4 \%$ & $2 \%$ & $4.4 \%$ & $2.6 \%$ & $\begin{array}{l}2.1 \\
\%\end{array}$ & $4.4 \%$ & $0.4 \%$ & $1.7 \%$ \\
\hline
\end{tabular}

\section{Conclusion:-}

Endometrium with no significant pathology was seen in most of the cases. Anovulatory bleeding was common in the perimenopausal woman. Among organic causes, pregnancy related AUB was the most common cause in the reproductive age .Malignancy is common in post menopausal woman. As endometrial hyperplasia is a precursor of endometrial carcinoma, it is important that histopathological examination is done generously in woman presenting with AUB especially after the age of 40 years to rule out malignant pathology.

\section{References:-}

1. Khans, Hameed S, Umber A, Histopathological Pattern of Endometrium on Diagnostic D \& C in patient with Abnormal Uterine Bleeding, ANNALS 2011; 17:166-70

2. K. Sajitha et al. study of histopathological pattern of endometrium in abnormal uterine bleeding CHRISMED, Journal of Health and Research year; 2014/volume:1/Issue:2/page:76-81

3. Shazia Fakhar, Gulshan Saeed, Amir Hussain Khan, Ali Yawar Alam. Validity of pipelle endometrial sampling in patient with abnormal uterine bleeding Ann Saudi Med 2008;28:188-191.

4. Bhoomika Dadhania, Gauravi Dhruva, Amit Agravat, Krupal pujara. Histopathological study of Endometrium in Dysfunctional uterine Bleeding. Int J. Res Med. 2013;2(1); 20-24.

5. Nadia Adnan Ghani, Aiad Abdular Abdul razak, Ehson Mahmood Abdulah Abnormal Uterine bleeding : a histopathological study Diyala Journal of Medicine Vol.4, Issue 1, April 2013.

6. Doraiswami Saraswati et al. Study of endometrial Pathology in Abnormal Uterine Bleeding. The Journal of Obstetrics and Gynecology of India (July August 2011) 61(4):426-430.

7. Dangal G. A study of endometrium of patients with abnormal uterine bleeding at chitwan valley. Kathmandu Univ Med J.2003;1:110-2.

8. Vijay Kumar, Navneet Kaur, Taposhi Das Manjit Singh Bal, Anil Kumar Suri Sonima, Sarbhjit Kaur and Balwinder Kaur correlation of various clinical findings and Chief Complains with Histopathological pattern of Endometrial Biopsies; A study of 300 Cases. Research and Reviews; Journal of Medical and Health Sciences. Vol. 3/issue (supplement 3)/July-September, 2014.

9. Muzzafar M, Akhtar KAK, Yasmin S, et al Menstrual irregularities with excessive blood loss. A clinico pathological correlation. JPMA 2005; 55: 486 